\title{
Potential of palm biomass as renewable energy source from data analysis of Sua Manggis palm oil mill in Linggi, Negeri Sembilan, Malaysia
}

\author{
W. J. $\mathrm{Ng}^{1}$, A. A. Rahman ${ }^{2}$ \& S. L. Koh ${ }^{1}$ \\ ${ }^{1}$ School of Physical Science and Engineering, \\ Heriot-Watt University, Malaysia \\ ${ }^{2}$ Centre for Renewable Energy, Universiti Tenaga Nasional, Malaysia
}

\begin{abstract}
There are various types of renewable energy such as wind, tidal, solar, hydro, geothermal heat, as well as biomass or biogas. One renewable energy resource that has good potential in Malaysia is biomass, which is harvested from agricultural residue. Apart from hydroelectric generators which use water to run, solar energy from sunlight, or wind turbines, which are more popular worldwide. The biomass energy is the most practical way to produce energy because Malaysia has an abundance of natural resources. Malaysia's governmental energy policy encourages the palm oil industry to be achieving zero waste in palm oil industry and sustainable palm oil residue as biomass energy. Thus, this research project will focus on the potential of biomass energy that can be gained from the biggest producer of biomass in Malaysia - the palm oil industry. Palm oil grows all around Malaysia since the climate is very suitable. As the number of palm oil mills is increasing, so does the biomass resource for green energy. From the analysis data we can define palm oil mill (POM) production as well as potential types of fuel, and the improvements for POM milling process. This research will define the potentials of palm biomass in becoming a green energy producer.
\end{abstract}

Keywords: palm oil mill (POM), potential energy, fresh fruit bunch (FFB).

\section{Introduction}

Biomass energy makes up to 10 percent of global energy use [1]. The biomass energy usage is rapidly growing. Biomass is using biological material derived from living, or recently living organisms mostly refer to plant or plant-based 
material like wood, oil palm residue, municipal waste and rice husk. Renewable energy has various type resources, but renewable energy resources depend on geographical area. In Malaysia, there are geographical areas easily to harvest biomass and solar energy compare to other renewable resources. The biomass energy have three types are solid biomass, liquid bio-fuel and biogas, but normally liquid bio-fuel is for the transportation sector. Biomass energy can be used to ensure the energy security and sustainability in the future. Palm oil industry offer great potential of biomass wastes for the power generation industry.

From the availability of the palm-based biomass, proved that have a huge potential to convert those biomass into good value products and can be create up to billion dollar business model. According to the statistics from United States Department of Agriculture, palm oil is the world largest vegetable oil production in 2012/2013, between a year's vegetable oils production is 55.29 million tonnes out of 159.64 million tonnes [2]. The global palm oil production from various countries in 2012/2013 is showing in Figure 1. As shown from the figure, Malaysia and Indonesia of both countries are world's largest producers accounting as $34 \%$ and $52 \%$ of world production.

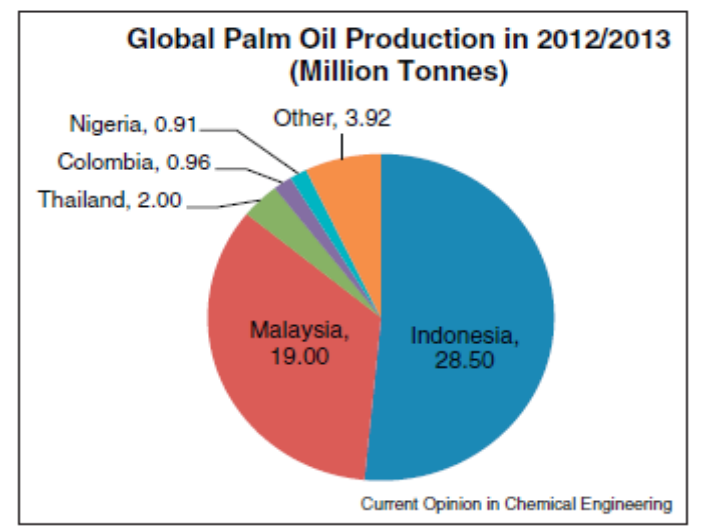

Figure 1: Global palm oil production 2012/2013 (United States Department of Agriculture (USDA): Oilseeds: World Market and Trade, 2013 [5]).

From the statistics it is shown that Malaysia, as a major player in the palm oil and starch industries, can produce a substantial amount of agriculture residue as biomass waste, it is proven that have great opportunity to harness biomass energy in an eco-friendly and commercially-viable manner. Malaysia produces large amounts of wood and agriculture residue, the bulk of which are not being currently utilized for any downstream operations. The major agricultural crops grown in Malaysia are rubber $(39.67 \%)$, oil palm $(34.56 \%)$, cocoa $(6.75 \%)$, rice $(12.68 \%)$ and coconut (6.34\%) [3].

In the palm oil milling process of oil palm fruits known as fresh fruit bunch (FFB), palm-based biomass such as empty fruit bunches (EFBs), palm kernel shell (PKS), palm mesocarp fibre (PMF), palm kernel cake (PKC) and palm oil mill effluent (POME) are produced [1]. 


\subsection{Palm oil mills process}

Through certain process palm oil and palm kernel oil are extracted from mesocarp and kernels respectively. The percentage of oil palm residue according to matrix oil palm mill process and based on Malaysia Tenera Material with $25 \%$ oil content [2].

In general, an average content of the fresh fruit bunch (FFB) is $25 \%$ oil, $5.5 \%$ palm kernel cake, $6 \%$ palm kernel shell, $9 \%$ palm mesocarp fibre, $25 \%$ (excluding moisture) empty fruit bunch (EFB) and the balance is moisture [2]. All this parts in palm oil can produce green energy by getting through specific process for each material. Figure 2 shows the simple palm oil mill (POM) process diagram that come from the FFB and will get through process and will get EFB, shell, POME and other waste.

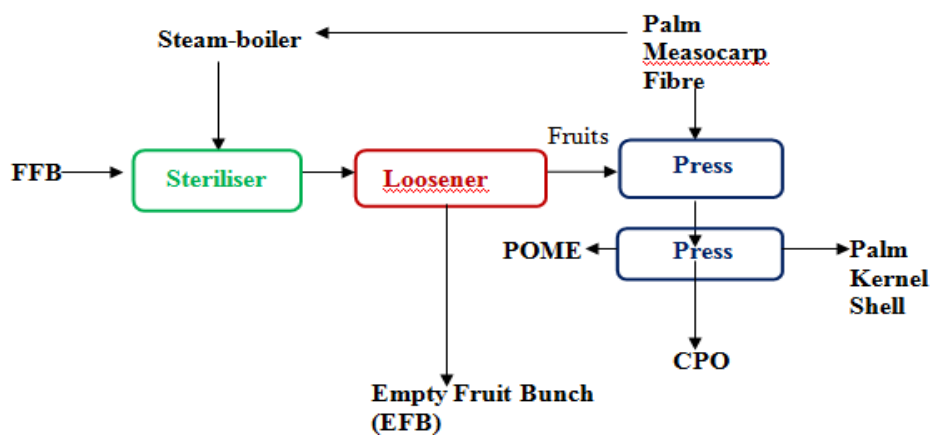

Figure 2: Palm oil mill (POM) process diagram.

\section{Methodology}

Project methodology is the process to auditing the project. This project started by compiling all the important information related to POM process, boiler efficiency, and fuel moisture content. The entire research steps are based on the research that has been done in the literature review.

Then from all the data, the calculation on potential energy can be determined by the boiler efficiency. The potential then will times with the number of palm oil mills with the same capacity all around Malaysia. As the result we can get the overall of potential green energy for POM based on their capacity.

\subsection{Project planning}

Research project planning is the flow of the project from the first step until the last step on research project. Research project planning have been drawn in the proposal before continuing the project to make sure this project is on the track as in Figure 3. The methodology of the project helped the author to give guideline to complete this project is step by step. Furthermore the timeline assisted the project to have been done following the give schedule. 
- Literature review on Palm Oil Mills industries

- Literature review on process flow of Palm oil mills

- Site visit to Palm Oil Mill (POM)

- Collecting data

- Connecting and relating the data and ideal result

Figure 3: Project planning flow chart.

\section{Results and discussion}

\subsection{Formulate calculation}

\subsubsection{Potential energy}

For the potential energy from the surplus biomass, the fuel available minus the fuel needed will give the extra fuel unused. The equations below can be used for both mesocarp fibre and palm kernel shell:

Mesocarp fibre/Palm kernel shell:

$$
\dot{\mathrm{m}}_{\text {potential }}=\dot{\mathrm{m}}_{a v}-\dot{\mathrm{m}}_{\text {req }}
$$

where

$\dot{\mathrm{m}}_{\text {potential }}=$ mass of surplus biomass

$\dot{\mathrm{m}}_{a v}=$ mass of fuel available

$\dot{\mathrm{m}}_{\text {req }}=$ mass of fuel required

\subsubsection{Calorific value}

Calorific value is used to determine potential energy from surplus biomass. And to get calorific value the equation is:

$$
C V=C V_{d}(1-m)
$$

Calorific Value (Dry Weight $)=\frac{\text { Calorific Value }(\text { Actual Weight })}{(1-M)}$

where

$C V=$ calorific value

$C V_{d}=$ dry calorific value

$m=$ moisture percentage 


\subsubsection{Potential energy}

The potential energy for each biomass will be determined by times the mass and the calorific value the equations are:

Mesocarp fibre:

$$
E_{\text {Fibre }}=\dot{\mathrm{m}}_{\text {Fibre }} \times C V
$$

Palm kernel Shell:

$$
E_{\text {Shell }}=\dot{m}_{\text {Shell }} \times C V
$$

Empty fruit bunch (EFB):

$$
E_{E F B}=\dot{m}_{E F B} \times C V
$$

This green energy in each POM is a combination of the amount of the potential energy gain from mass balance of each biomass. The green energy potential data is determined using this equation:

$$
E_{\text {Total }}=E_{\text {Fibre }}+E_{\text {shell }}+E_{E F B} \quad(k W)
$$

The amount of total green energy then will be estimated times with the number of the POM based on their capacity to get the total green energy for the POM all over Malaysia. This result can be determined by this equation:

$$
E_{C}=E_{T} \times N_{c}
$$

where

$E_{C}=$ potential energy for POM with specific capacity in Malaysia

$E_{T}=$ total potential energy for each POM

$N_{c}=$ number of POM with specific capacity in Malaysia

The total potential energy calculates is ideal case amount, it can be large amount of energy to generate large amount of electricity. In practical case, need to be considering boiler and steam turbine efficiency.

\subsubsection{Total potential electricity of palm oil mill (POM)}

Electricity efficiency $=$ boiler efficiency $\times$ Steam turbine and generator efficiency. Total potential electricity $=$ total amount of potential energy, $E_{\text {Total }} \times$ electricity efficiency.

\subsection{Data analysis graph}

\subsubsection{Oil palm production}

Every month BELL-KSL oil palm mill have data of total amount of oil palm mill they are produced and processing hour. Figure 4 shows the amount of palm biomass residues generated. Three types of oil palm residue can be feed into the boiler, namely empty fruit bunch, mesocarp fibre and palm kernel shell. 


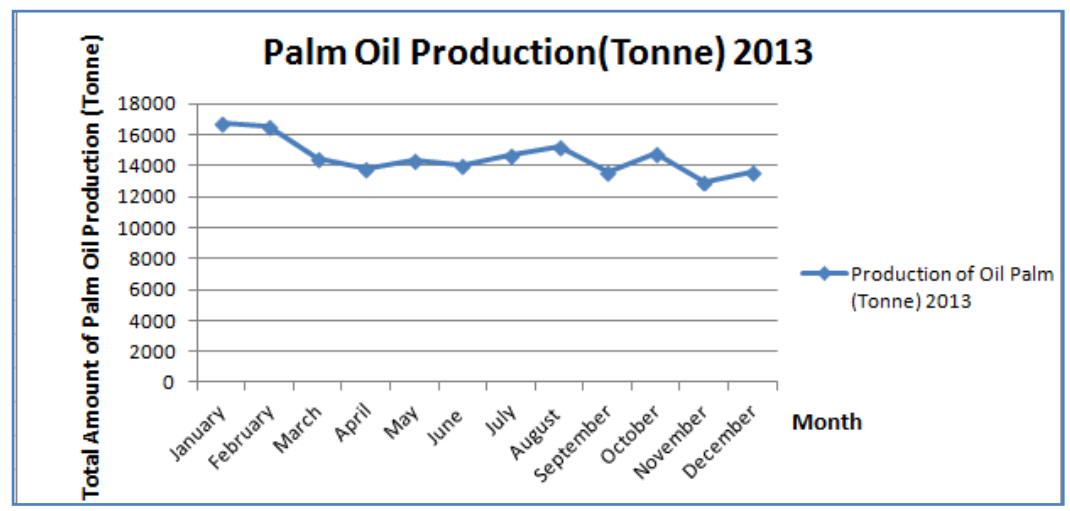

Figure 4: $\quad$ Production of palm oil.

The data shows that, every month total amount of oil palm production is affect by climate change or weather. The production amount needs to be considering capability of palm oil mill, not every palm oil mill can be handling huge amount of oil palm production. For instance, El-Nino weather phenomenon will affect the growth of palm oil tree and production of palm oil.

\subsubsection{Average production of oil palm and oil palm waste by per hour in every month}

Average per year can be producing 27.6 T (tonnes per hour). Different types of POM have different amount of plant capacity. BELL-KSL Lorong Sua Manggis, Linggi mill, is 30 tonne per hour, but always in fixed, sometimes will be more, sometimes will be less, main reason depend on weather.

$$
\text { Average Mill Capacity per Hour }=\frac{\text { Fresh Fruit Bunch }}{\text { Processing Hour }}
$$

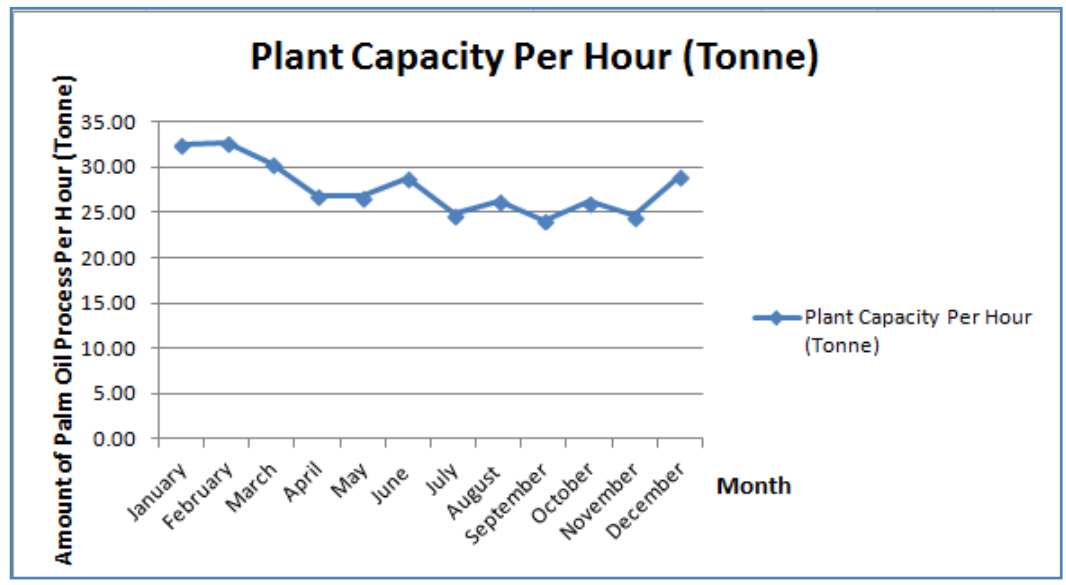

Figure 5: Plant capacity per hour (tonne). 


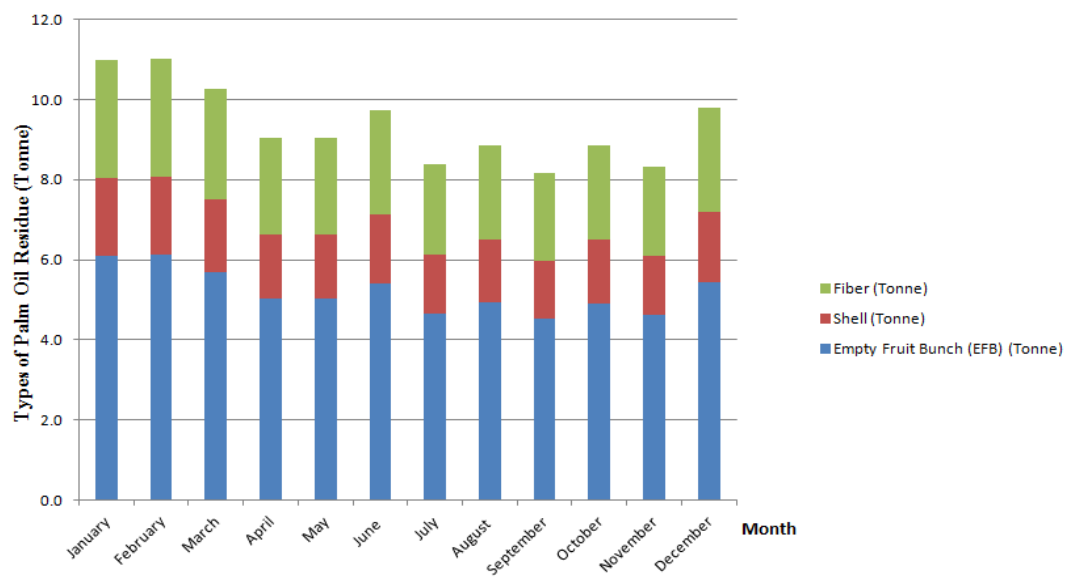

Figure 6: Oil palm residue, Mesocarp Fibre, palm kernel shell and empty fruit bunch (EFB) (tonne).

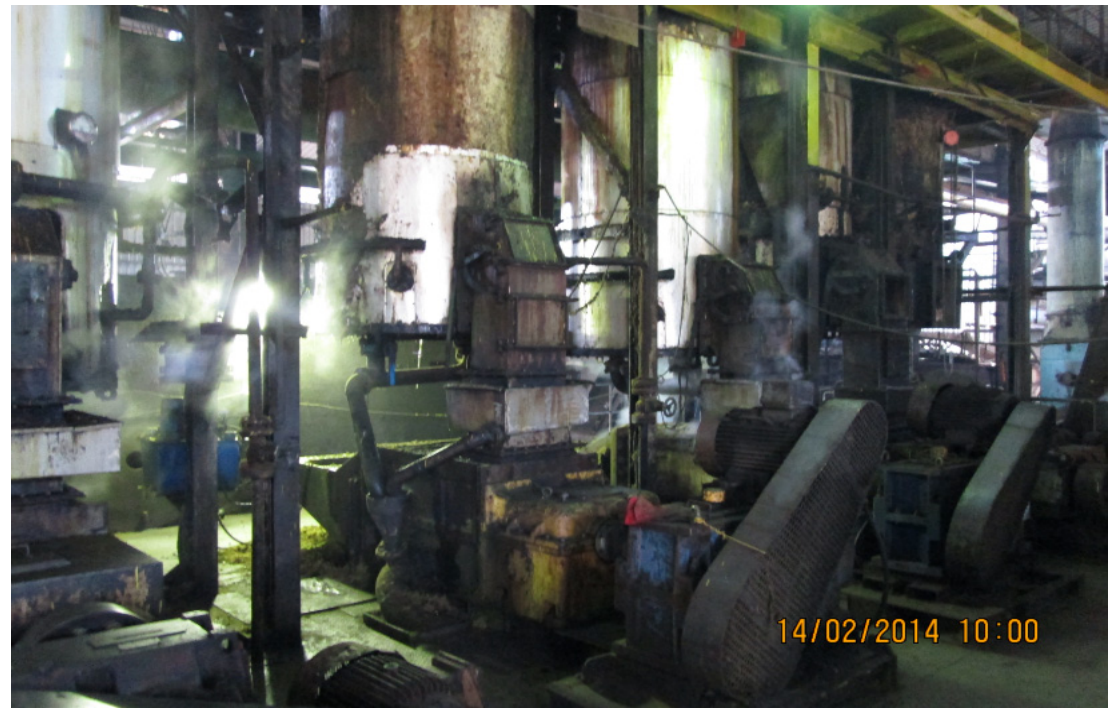

Figure 7: Sua Manggis palm oil mill fresh fruit bunch process.

\subsubsection{Palm oil mill current operational surplus electricity and total potential electricity $(\mathrm{kW})$}

According to the mill, mill need to use 25 Kilowatt fresh fruit bunch per ton per hour [3] BELL-KSL palm oil mill have ideal case consumption statistic data and ideal amount of electricity can be generating by steam turbine, palm oil mill itself didn't recorded the amount of electricity consumption and amount of electricity generate by the palm oil mill. Currently, BELL-KSL can't provide exact amount of electricity generated. The process is in pilot case. 
The electricity consumption of palm oil mill is plant capacity per hour multiply with twenty five thousand watt. The steam turbine can be generating 1.6MW. Surplus electricity for export is generating electricity minus electricity consumption of oil palm mill. The figures below show the electricity consumption of palm oil mill and surplus electricity for export.

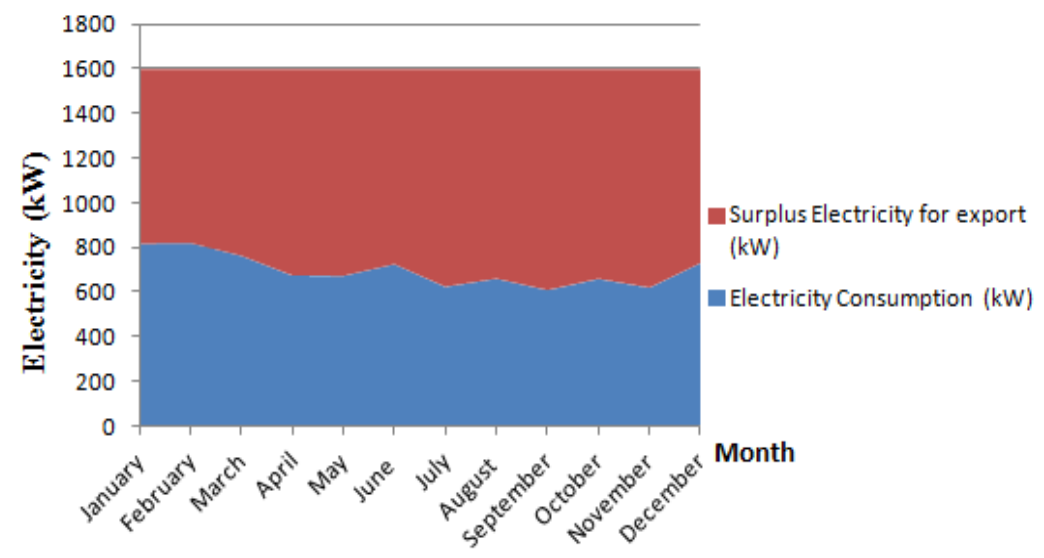

Figure 8: Operational surplus electricity $(\mathrm{kW})$.

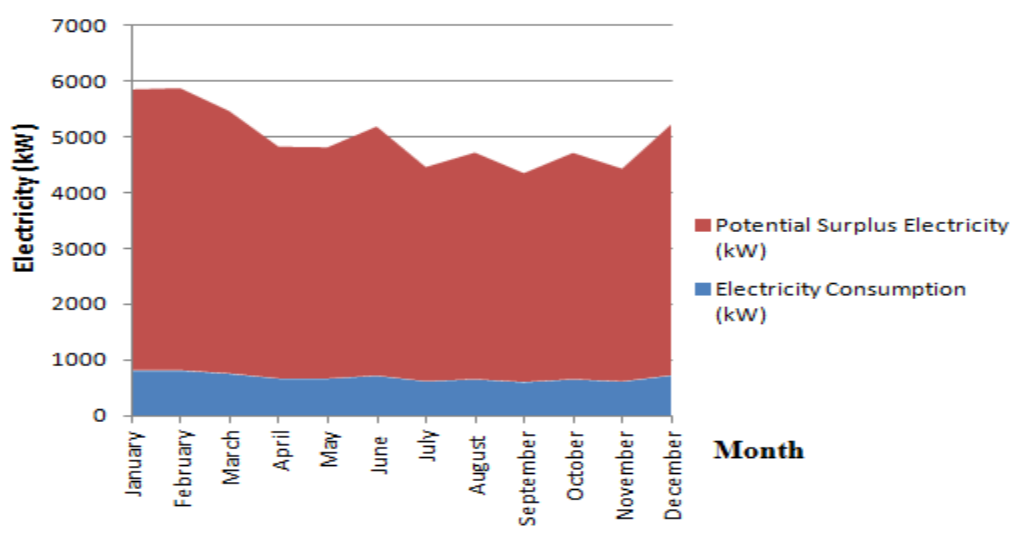

Figure 9: Total potential electricity $(\mathrm{kW})$ and POM electricity consumption $(\mathrm{kW})$.

From the Figure 8 graph above is operational surplus electricity $(\mathrm{kW})$. In practical case, accurate amount of generate electricity is fluctuation depend on the total amount of palm oil production, boiler efficiency, moisture content of palm oil waste. Figure 9 graph is total potential electricity include the fuel ratio and electricity efficiency, but compare with the Figure 8 graph more efficient to generate electricity. In BELL-KSL Lorong Sua Manggis, Linggi, palm oil mill is biomass pilot plant. 


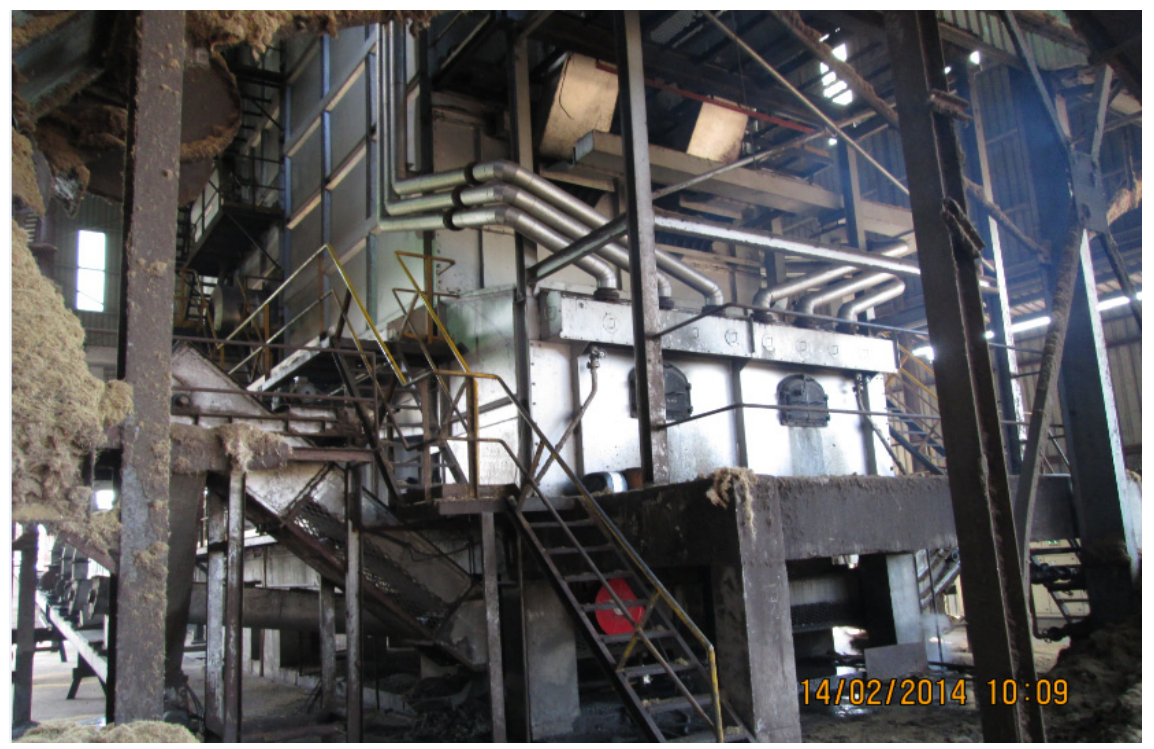

Figure 10: Sua Manggis palm oil mill boiler.

\section{Conclusions}

This research project starts by compile all the important information relates to the process flow of POM to come out with the potential energy by POM and improvement in process flow and process technology. From all the data evaluate, the potential of POM as green energy producer is decided.

The research on the potential green energy in POM explains that biomass could be a great resource to replace fossil fuel as the fuel to power plant. This has come to one of the solution to the power sources in our country. The research on biomass potential only considers the surplus of the solid fuel. Besides that, the research on efficiency of the boiler also could be done to maximize the use of fuel to avoid waste. With all the recommendation, it shows that the POM really has potential as green energy procedure.

\section{References}

[1] N. Abdullah and F. Sulaiman, "The Oil Palm Wastes in Malaysia," 2011. [Online]. Available: http://www.intechopen.com/books/biomass-nowsustainable-growth-and-use/the-oil-palm-wastes-in-malaysia. [Accessed 17 May 2014].

[2] H. Zulkikli, M. Halimah, K. W. Chan and Y. M. a. M. B. W. Choo, "Life Cycle Assessment for Oil Palm Fresh Fruit Bunch Production From Continued Land Use For Oil Palm Planted On Mineral Soil," Journal of Oil Palm Research, vol. 22, pp. 887-894, 2010.

[3] N. Wambeck, Oil Palm Mill, Systems And Process, 1999. 
[4] S. R. Schill, "Biomass Magazine," 2013. [Online]. Available: http://biomassmagazine.com/articles/9444/iea-task40-biomass-provides-10percent-of-global-energy-use. [Accessed 23 May 2014].

[5] United States Department of Agriculture (USDA): Oilseeds: World Market and Trade, 2013, "United States Department of Agriculture (USDA)," 2013. [Online]. Available: http://www.fas.usda.gov/psdonline/. [Accessed 26 May 2014].

[6] Selva, "MPOC," 2014. [Online]. Available: http://www.mpoc.org.my/The Oil Palm Tree.aspx. [Accessed 26 January 2014]. 